\title{
Endoscopic endonasal resection of skull base chondrosarcomas: technique and early results
}

\author{
Nelson Moussazadeh, MD, ${ }^{1}$ Charles Kulwin, MD, ${ }^{2}$ Vijay K. Anand, MD, ${ }^{3}$ Jonathan Y. Ting, MD, ${ }^{4}$ \\ Caryn Gamss, MD, ${ }^{5}$ J. Bryan lorgulescu, BA, ${ }^{1}$ Apostolos John Tsiouris, MD, ${ }^{5}$ \\ Aaron A. Cohen-Gadol, MD, MSc, ${ }^{2}$ and Theodore H. Schwartz, MD ${ }^{1,3,6}$
}

\begin{abstract}
Departments of ${ }^{1}$ Neurological Surgery, ${ }^{3}$ Otolaryngology, ${ }^{5}$ Radiology, and ${ }^{6}$ Neurology and Neuroscience, Weill Cornell Medical College, NewYork-Presbyterian Hospital, New York, New York; ${ }^{2}$ Goodman Campbell Brain and Spine and Department of Neurosurgery, and ${ }^{4}$ Department of Otolaryngology, Indiana University School of Medicine, Indianapolis, Indiana
\end{abstract}

\begin{abstract}
OBJECT The authors of this study sought to report the technique and early clinical outcomes of a purely endonasal endoscopic approach for resection of petroclival chondrosarcomas.
\end{abstract}
METHODS Between 2010 and 2014, 8 patients (4 men and 4 women) underwent endonasal endoscopic operations to resect petroclival chondrosarcomas at 2 institutions. The patients' mean age was 44.8 years (range 30-64 years). One of the patients had previously undergone radiation therapy and another a staged craniotomy. Using volumetric software, an independent neuroradiologist assessed the extent of the resections on MRI scans taken immediately after surgery and at the 3-month follow-up. Immediate complications and control of symptoms were also recorded. In addition, the authors reviewed the current literature on surgical treatment of chondrosarcoma.

RESULTS The mean preoperative tumor diameter and volume were $3.4 \mathrm{~cm}$ and $9.8 \mathrm{~cm}^{3}$, respectively. Six patients presented with cranial neuropathies. Endonasal endoscopic surgery achieved $>95 \%$ resection in 5 of the 8 patients and < $95 \%$ resection in the remaining 3 patients. One of the 6 neuropathies resolved, and the remaining 5 partially improved. One instance of postoperative CSF leakage required a reoperation for repair; no other complications associated with these operations were observed. All of the patients underwent adjuvant radiotherapy.

CONCLUSIONS According to the authors' experience, the endoscopic endonasal route is a safe and effective approach for the resection of appropriately selected petroclival chondrosarcomas.

http://thejns.org/doi/abs/10.3171/2014.11.JNS14827

KEY WORDS chondrosarcoma; clivus; minimally invasive; neuroendoscopy; petrous apex; skull base; transpterygoid approach; oncology; pituitary surgery

I NTRACRANIAL chondrosarcoma is a rare and indolent, but locally aggressive, tumor arising from chondrocytes or their precursor cells involved in endochondral ossification at the skull base. Occurring most commonly at the petroclival junction, these tumors comprise approximately $0.2 \%$ of all intracranial tumors and $6 \%$ of skull base tumors., ${ }^{3,5,23}$ A recent meta-analysis estimated that the 5 -year postoperative recurrence rate of chondrosarcoma is $22 \%$, and the overall survival rate of patients with the disease is $88.5 \% .{ }^{4}$ Known prognostic factors for both tumor recurrence and patient survival include histological grade (that is, a grade of I-III based on tumor differentia- tion), type (with worse outcomes in cases of mesenchymal and dedifferentiated variants than in conventional hyaline/ myxoid or clear cell variants), and treatment with adjuvant radiotherapy. ${ }^{4}$

Contemporary management strategies consisting of resection in combination with adjuvant radiotherapy offer significant local control of chondrosarcoma and improve patient survival. Open approaches, including extended subfrontal-transbasal, transtemporal, far-lateral, transfacial, and combined or staged approaches, are the traditional corridors to the ventral midline skull base for operation of chondrosarcomas. These routes require large craniotomies

SUBMITTED April 11, 2014. ACCEPTED November 18, 2014.

INCLUDE WHEN CITING Published online January 16, 2015; DOI: 10.3171/2014.11.JNS14827.

DISCLOSURE Dr. Schwartz reports having stock options in Visionsense. 
and cerebral retraction and result in corridors in which critical neurovascular structures are interposed between the surgeon and the lesion. As such, open surgery results in morbidity and mortality rates of $25 \%-41 \%$ and up to $5 \%$, respectively. ${ }^{13,25,26,31}$ Given the difficulty in safely accessing the petroclival junction, endonasal endoscopic approaches, such as the transpterygoidal approach, were developed to improve the safety of surgery in this area..$^{15}$

Extended endonasal skull base osteotomies using endoscopy are increasingly used for exposure and resection of tumors in the paramedian skull base. These minimally invasive routes hold particular promise for treating chondrosarcomas that originate in the petroclival junction with involvement of the petrous apex, Meckel's cave, Dorello's canal, or cavernous sinus. Chondrosarcomas typically have a soft consistency and do not invade the surrounding neurovascular structures. Therefore, they are good candidates for resection through the endoscopic route. Similar approaches to the clivus and paraclival ventral skull base involving transpterygoid or transethmoidal cavernous sinus corridors have been reported to provide local tumor control and reduce complication rates in the treatment of a variety of tumors. $8,11,17,19,28$

Because chondrosarcomas respond to radiation therapy, maximal safe resection is the guiding principle. Case reports and small surgical series have yielded some promising results with extended endoscopic transsphenoidal approaches to chondrosarcomas in the skull base. ${ }^{9,10,20,21,33} \mathrm{We}$ report our experience with the largest single series of chondrosarcoma patients to date and discuss the applicability, utility, and outcome of the extended endonasal approaches for treating this challenging skull base tumor.

\section{Methods}

Our institutional review board approved this study. A retrospective chart review was performed of prospectively acquired data of patients who underwent fully endoscopic endonasal tumor resections between 2010 and 2014 at the NewYork-Presbyterian Hospital-Weill Cornell Medical Center and at Goodman Campbell Brain and Spine of the Indiana University Department of Neurosurgery. Cases involving a lesion indicative of chondrosarcoma were included in the present study. Demographic information of the patients was obtained, along with symptoms, size, and location of lesions; history of surgeries and radiotherapy; time and technique of operations; use of adjuvant therapy; and outcomes of the surgical interventions.

The preoperative tumor volume was measured using Advantage Workstation 4.3 and Volume Viewer 2 (GE Healthcare) on preoperative image-guidance Gd-enhanced MRI scans. The volumetric extent of the resections was determined by examining immediate postoperative scans and 3-month follow-up scans; this analysis was performed by a neuroradiologist who was blinded to the pathological diagnosis and the clinical history of the disease. ${ }^{12}$ On the basis of these findings, patients were divided into 2 groups: those with resections $>95 \%$ (used as a surrogate for complete resection because of the limitation of MRI for differentiating small remnants of tumors from surrounding tissues) and those with resections $<95 \%$.

\section{Surgical Technique: Extended Endonasal Endoscopic Approach to the Skull Base}

A team that included an otolaryngologist and a neurological surgeon performed all endonasal endoscopies of the skull base in this study. Five cases involved the use of intrathecal fluorescein $(0.25 \mathrm{ml}$ of $10 \%$ fluorescein with $10 \mathrm{ml}$ of CSF injected via lumbar puncture or drain following diphenhydramine and dexamethasone administration) before the endoscopy to visualize any durotomies and to ensure adequate repair of the skull base. Fully endoscopic extended endonasal approaches were used in all cases as previously described. ${ }^{6,32}$ The choice of approach was based on the tumor's location and extension, given in Table 1. Briefly, extended variants of the endoscopic endonasal operation included transpterygoid and transmaxillary approaches for extensions of lateral petrous tumors, transethmoid and transsphenoid approaches for inferolateral cavernous sinus exposure, and a transclival approach for middle and inferior clival lesions (Figs. 1 and 2). Often, we used a combination of these corridors.

Resection within the petrous apex necessitated the use of $30^{\circ}$ and $45^{\circ}$ endoscopes for visualization. We concurrently used MRI- and CT angiography-based neuronavigation together with Doppler ultrasonography in all cases to locate the neighboring vascular anatomy. Initial bone removal over the petroclival region exposed the carotid artery along its petrous segment or its entry point into the cavernous sinus. This initial maneuver allowed the operator to remove additional bone parallel to the artery and to protect it during the later stages of the operation. Skeletonization of the petrous carotid artery was necessary to mobilize the artery laterally to excise tumor tissue behind it. If tumor extension into the cavernous sinus was noted, the tumor encasing the carotid artery was removed until the cavernous sinus was entered along the artery. On encountering bleeding from this venous sinus, we used Floseal Hemostatic Matrix (Baxter) and Gelfoam (Pfizer) to seal the defect. Small ring curettes were used along the artery to reach into the cavernous sinus and remove the intracavernous extension of the tumor. Angled endoscopes $\left(45^{\circ}\right)$ and instruments were critical for resection of the tumors behind and lateral to the petrous carotid. On completion of tumor resection, the lateral clival and middle fossa dura were exposed (Fig. 1). The bony edges of the resection cavity were then curetted to maximize resection of the affected bone. Intradural extension of the tumors was removed at the site of their penetration into the intradural space.

All lesions were located primarily extradurally with small intradural extensions in 4 cases; durotomies in these cases were repaired with fat autograft covered with a nasoseptal flap and DuraSeal (Covidien). Lumbar drainage, for those cases in which it was used, was continued at 5 $\mathrm{cm}^{3} /$ hour for 1-2 days after the surgery.

\section{Literature Review}

We performed a PubMed search to identify previous reports of patients undergoing endoscopic endonasal resection of pathologically confirmed chondrosarcomas of the skull base. Reports were included if they described patient and lesion characteristics (including location and size); extent of the resection; use of adjuvant radiotherapy; 
TABLE 1. Clinical characteristics of the patients in this study

\begin{tabular}{|c|c|c|c|c|c|c|c|c|}
\hline \multirow[b]{2}{*}{$\begin{array}{l}\text { Case } \\
\text { No. }\end{array}$} & \multirow[b]{2}{*}{$\begin{array}{l}\text { Age (yrs), } \\
\text { Sex }\end{array}$} & \multirow[b]{2}{*}{$\begin{array}{c}\text { Signs/Symptoms at } \\
\text { Presentation }\end{array}$} & \multicolumn{3}{|c|}{ Tumor Characteristic } & \multirow[b]{2}{*}{ Prior Tx } & \multirow[b]{2}{*}{$\begin{array}{l}\text { Intraop CSF } \\
\text { Leakage }\end{array}$} & \multirow[b]{2}{*}{$\begin{array}{l}\text { Op Time } \\
\text { (mins) }\end{array}$} \\
\hline & & & $\begin{array}{l}\text { Dimensions } \\
\quad(\mathrm{cm})\end{array}$ & $\begin{array}{l}\text { Vol } \\
\left(\mathrm{cm}^{3}\right)\end{array}$ & Location & & & \\
\hline 1 & $49, \mathrm{~F}$ & CN III \& VI palsy & $3.5 \times 2.0 \times 2.5$ & 11.0 & $\begin{array}{l}\text { Petrous apex \& cav- } \\
\text { ernous sinus }\end{array}$ & None & Yes & 165 \\
\hline 2 & $48, M$ & Hemianopia, partial CN III palsy & $4.0 \times 2.6 \times 2.3$ & 6.6 & Petrous apex & Staged craniotomy & No & 105 \\
\hline 3 & $30, F$ & CN III palsy & $3.6 \times 2.1 \times 2.6$ & 11.2 & $\begin{array}{l}\text { Petrous apex \& cav- } \\
\text { ernous sinus }\end{array}$ & Single-dose SRS & Yes & 251 \\
\hline 4 & $42, \mathrm{M}$ & CN VI palsy & $2.8 \times 2.6 \times 2.2$ & 8.0 & $\begin{array}{l}\text { Petrous apex, CPA, \& } \\
\text { cavernous sinus }\end{array}$ & None & No & 306 \\
\hline 5 & $64, \mathrm{M}$ & CN VI palsy & $3.5 \times 3.2 \times 2.7$ & 14.3 & Petrous apex \& CPA & None & Yes & 298 \\
\hline 6 & $44, \mathrm{M}$ & None* & $4.1 \times 2.7 \times 4.1$ & 17.7 & Petrous apex & None & No & 387 \\
\hline 7 & $47, \mathrm{~F}$ & CN V hypesthesia \& pain & $2.2 \times 2.2 \times 2.5$ & 3.4 & $\begin{array}{l}\text { Petrous apex \& cav- } \\
\text { ernous sinus }\end{array}$ & None & Yes & 256 \\
\hline 8 & $34, F$ & None $^{*}$ & $3.1 \times 1.6 \times 2.1$ & 5.8 & Petrous apex & None & No & 346 \\
\hline
\end{tabular}

$\mathrm{CN}=$ cranial nerve; $\mathrm{CPA}=$ cerebellopontine angle; $\mathrm{SRS}=$ stereotactic radiosurgery; $\mathrm{Tx}=$ treatment.

* Diagnosis of chondrosarcoma was incidental in this patient.

and outcome data including CSF leakage and other surgical complications, tumor recurrence, and patient survival.

\section{Results}

Between February 2010 and March 2014, 8 patients (4 men and 4 women) underwent endoscopic endonasal resections to treat petroclival chondrosarcomas. During this time period, 5 additional patients were treated at our institutions for chondrosarcoma via a transcranial route. The open approaches were chosen when lesions had a significant lateral petrous extension and were poorly accessible from a paramedian endoscopic transnasal corridor.

The mean age of the 8 patients was 44.8 years (range
30-64 years). Neurological symptoms at presentation included cranial neuropathies in 6 of the 8 patients, and chondrosarcoma was newly diagnosed in 7 patients. Three of these patients exhibited oculomotor nerve palsy and 3 abducens nerve palsies. Of these, 1 patient had chondrosarcoma involving multiple compartments, including a large degree of lateral suprasellar tumor extension and optic nerve compression. This patient underwent a craniotomy first to remove the suprasellar compartment of the tumor. The tumor within the petroclival area was then resected through a staged endonasal approach. Another patient had a previous biopsy followed by stereotactic radiotherapy, and tumor progression in this patient necessitated further endonasal surgery.
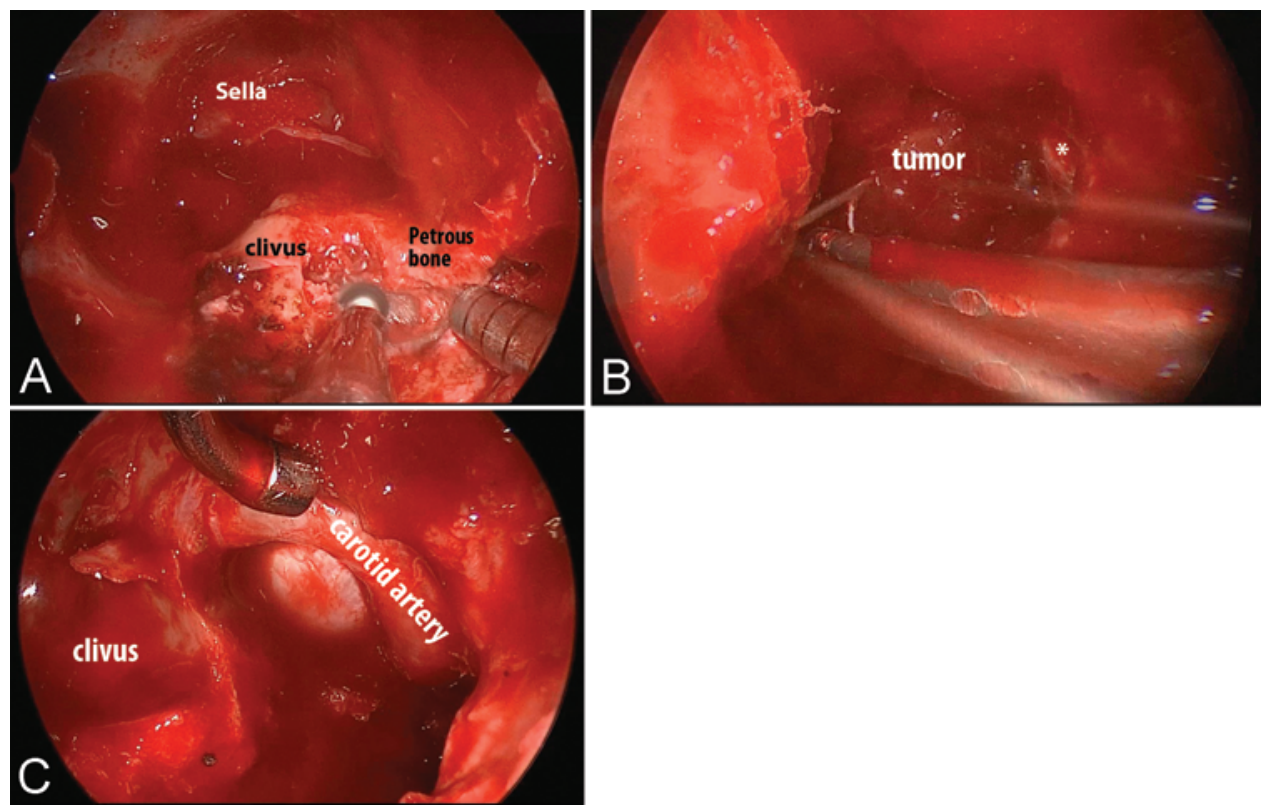

FIG. 1. Extended endonasal approach to the cavernous and petroclival regions. A: Initial bone drilling exposes the tumor housed in the petroclival region. B: Angled scopes and instruments are used to remove the tumor behind the carotid artery. C: At the end of resection, the carotid artery and dura along the middle fossa are exposed. Figure is available in color online only. 


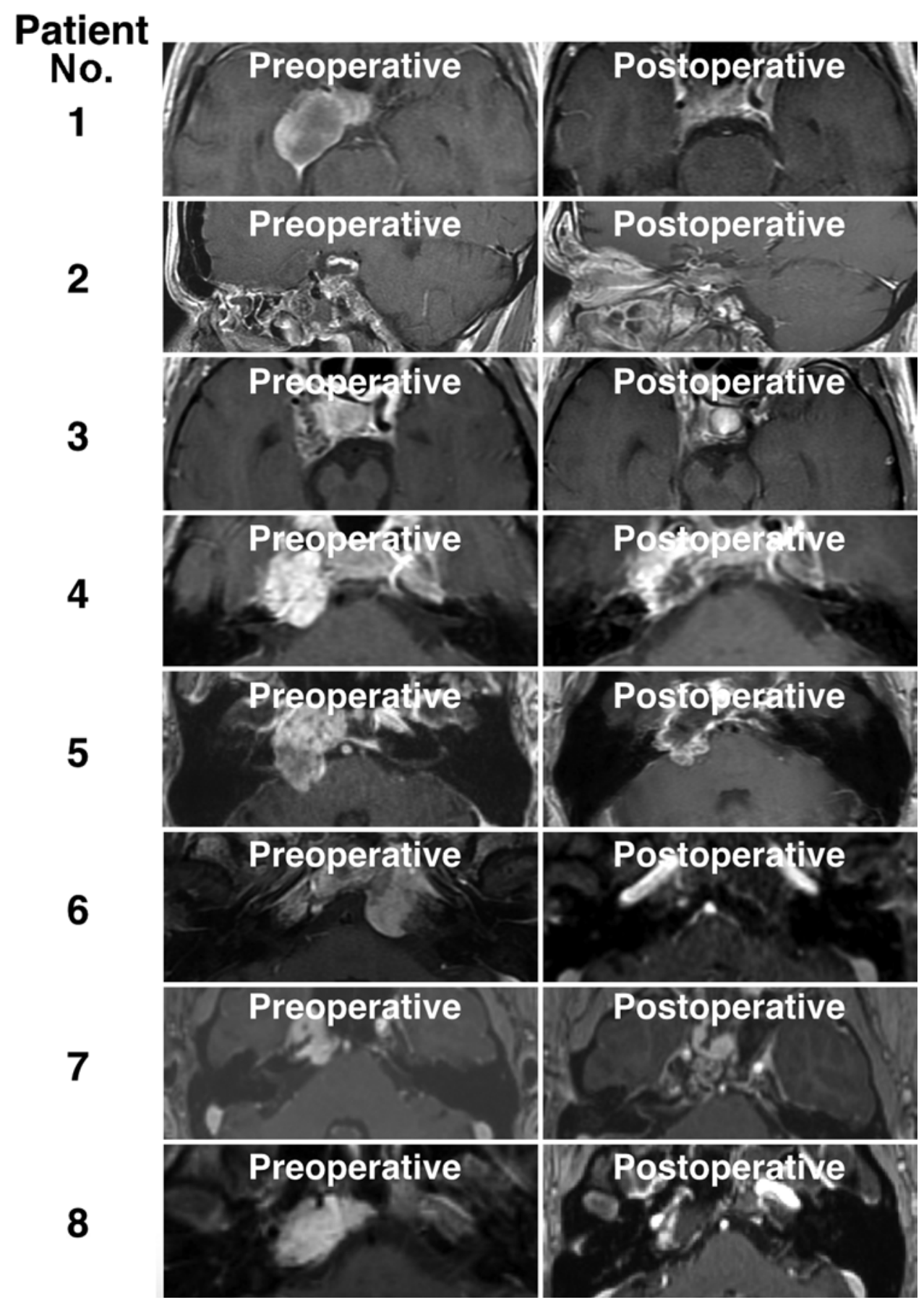

FIG. 2. Images of Gd-enhanced MRI sequences of the head before (left) and after (right) surgery that entailed endonasal endoscopic approaches to chondrosarcomas in the skull base; results are shown for the 8 patients in this study.

The mean preoperative tumor diameter in the largest plane was $3.35 \mathrm{~cm}$, and the mean tumor volume was 9.75 $\mathrm{cm}^{3}$ (Table 1). All tumors were centered over the petrous apex, 4 extended into the cavernous sinus, and 2 extended into the cerebellopontine angle. Two patients in whom a large CSF leak was anticipated received intraoperative CSF diversion via lumbar drainage; intraoperative CSF leakage was noted in 4 patients. The mean operative time was 264 minutes.

In 5 of the 8 patients $>95 \%$ of the tumor was removed
(Table 2). The mean extent of resection in this group was $97.6 \%$, and the mean volume of the residual tumor was $0.22 \mathrm{~cm}^{3}$. In 3 of the 8 patients $<95 \%$ resection was achieved; the mean extent of the resection in this group was $79.6 \%$, and the mean postoperative tumor volume was $1.77 \mathrm{~cm}^{3}$. Preoperative volumes did not significantly differ between these 2 groups (t-test; not significant at $\mathrm{p} \leq 0.05$ ). A postoperative CSF fistula was observed in 1 patient who did not appear to have a CSF leak during surgery but did not receive intrathecal fluorescein intraoperatively to iden- 
TABLE 2. Surgical outcomes in this study

\begin{tabular}{cclll}
\hline $\begin{array}{c}\text { Case } \\
\text { No. }\end{array}$ & $\begin{array}{c}\text { Extent of } \\
\text { Resection }\end{array}$ & Immediate Postop Complication & \multicolumn{1}{c}{ Clinical Outcome } & Adjuvant Tx \\
\hline 1 & GTR & None & $\begin{array}{c}\text { Diplopia improved s/p EOM recession/resection \& prism } \\
\text { NED, visual field deficits largely resolved except small superior } \\
\text { residual OU; diplopia improved to involve only upward \& } \\
\text { rightward (but not primary) gaze }\end{array}$ & Proton XRT \\
\hline 2 & STR & None & CN IIl palsy improved & Proton XRT \\
\hline 3 & GTR & $\begin{array}{l}\text { Fungal sinus infection w/o sequelae } \\
\text { s/p antimycotics }\end{array}$ & Diplopia resolved & Photon-proton XRT \\
\hline 5 & GTR & None & Diplopia improved & Proton XRT \\
\hline 7 & NTR & None & Proton XRT \\
\hline 8 & GTR & CSF leakage, nasoseptal flap repair & Intact* & Proton XRT \\
\hline NTR & None & Stable V1-2 hypesthesia, improved V3 sensation & Proton XRT \\
\hline
\end{tabular}

$\mathrm{EOM}=$ extraocular muscle; GTR = gross-total resection; NED = no evidence of disease; NTR = near-total resection; OU = oculus uterque (bilateral eyes); $/ \mathrm{p}=$ status post; STR = subtotal resection; XRT = x-ray therapy.

* The patient had no previous disease symptoms (the discovery of chondrosarcoma was incidental; see Table 1).

tify any CSF leakage. A second operation with nasoseptal flap repair successfully controlled the leakage.

Cranial neuropathies resolved in 1 of 6 patients who showed neurological deficits and partially improved in the remaining 5 patients (Table 2). In addition, a visual field deficit improved in 1 patient. One patient contracted fungal sinusitis, which resolved after a short course of antimycotics. No incidence of keratitis sicca or other manifestations of vidian neuropathy was observed, and no pituitary dysfunction, visual decline, or death was noted. All patients underwent proton-based or combination proton-photon adjuvant radiotherapy.

\section{Illustrative Case}

The patient in Case 4 (Table 1) reported diplopia and on examination was found to have a sixth cranial nerve palsy. An MRI scan revealed a mass within his petrous apex, just below the posterior cavernous genu of the internal carotid artery. An endonasal endoscopic transpterygoid approach was performed, and the tumor was removed (Fig. $3)$. Once tumor resection was completed with a $30^{\circ}$ endoscope, use of a $45^{\circ}$ endoscope permitted identification of a small amount of residual tumor that was located more laterally, which was also excised. No fluorescein leakage or frank durotomy was identified. Gelfoam controlled minor bleeding from the cavernous sinus, and Floseal was placed onto the resection cavity.

The patient recovered well and without any complications and underwent combined proton-photon adjuvant radiotherapy for pathologically confirmed low-grade chondrosarcoma. At the last (46-month) follow-up, the patient's diplopia had resolved, and an MRI scan showed no evidence of regrowth.

\section{Discussion}

Current treatment paradigms for chondrosarcoma of the cranial base include maximal cytoreductive surgery combined with adjuvant radiotherapy with various modalities. A meta-analysis of data from 560 patients who were treated for chondrosarcoma and followed up for a median time period of 60 months reported recurrence rates of $44 \%$ after surgery only, $19 \%$ after radiotherapy only, and $9 \%$ after a combination of surgery and radiotherapy. ${ }^{4}$ Surgery is a key component of this approach given 1) the importance of diagnosis (for example, to definitively differentiate chondrosarcoma from similar tumors such as chordoma); 2) the need for neurological decompression, particularly in young patients who show disease symptoms; and 3) the need to maximize the effectiveness and reduce the potentially neurotoxic effects of conformal radiation, which is an accepted treatment for controlling these tumors long term..$^{22}$

Historically, approaches including basal subfrontal, subtemporal, presigmoid infratemporal, and combined approaches, although frequently resulting in improved survival and better tumor control, also caused high morbidity rates. ${ }^{7,13}$ For example, a study of a patient series undergoing resection of transcranial chondrosarcoma reported new neurological deficits in 7 of 9 patients. These deficits included brainstem injury and hemiparesis, cranial neuropathies and hypopituitarism, as well as several cases of CSF leakage requiring operative repair. All patients undergoing subfrontal approaches incurred iatrogenic anosmia. ${ }^{27}$ A study of another large patient series, while reporting 5and 10 -year overall survival rates of $95 \%$, also observed postoperative neurological deficits in $33 \%$ of cases. ${ }^{25}$

Endoscopic endonasal approaches are increasingly used to remove extrasellar lesions. For example, the transpterygoid approach has emerged as an effective corridor to the foramen lacerum, the petrous internal carotid artery, Meckel's cave, the cavernous sinus, and the infratemporal fossa. ${ }^{18}$ To date, however, few reports exist on endonasal resection of chondrosarcomas. Chondrosarcomas frequently comingle with chordomas, and previous reports of the use of endoscopic endonasal resection have included only 1-2 patients in whom chondrosarcoma was diagnosed. These reports have shown that gross-total resection was efficacious in 5 of 8 patients (Table 3 ). Morbidity rates associated with endonasal resection are largely due to postoperative CSF leakage. Indeed, a case report by Li et al..$^{21}$ reported 

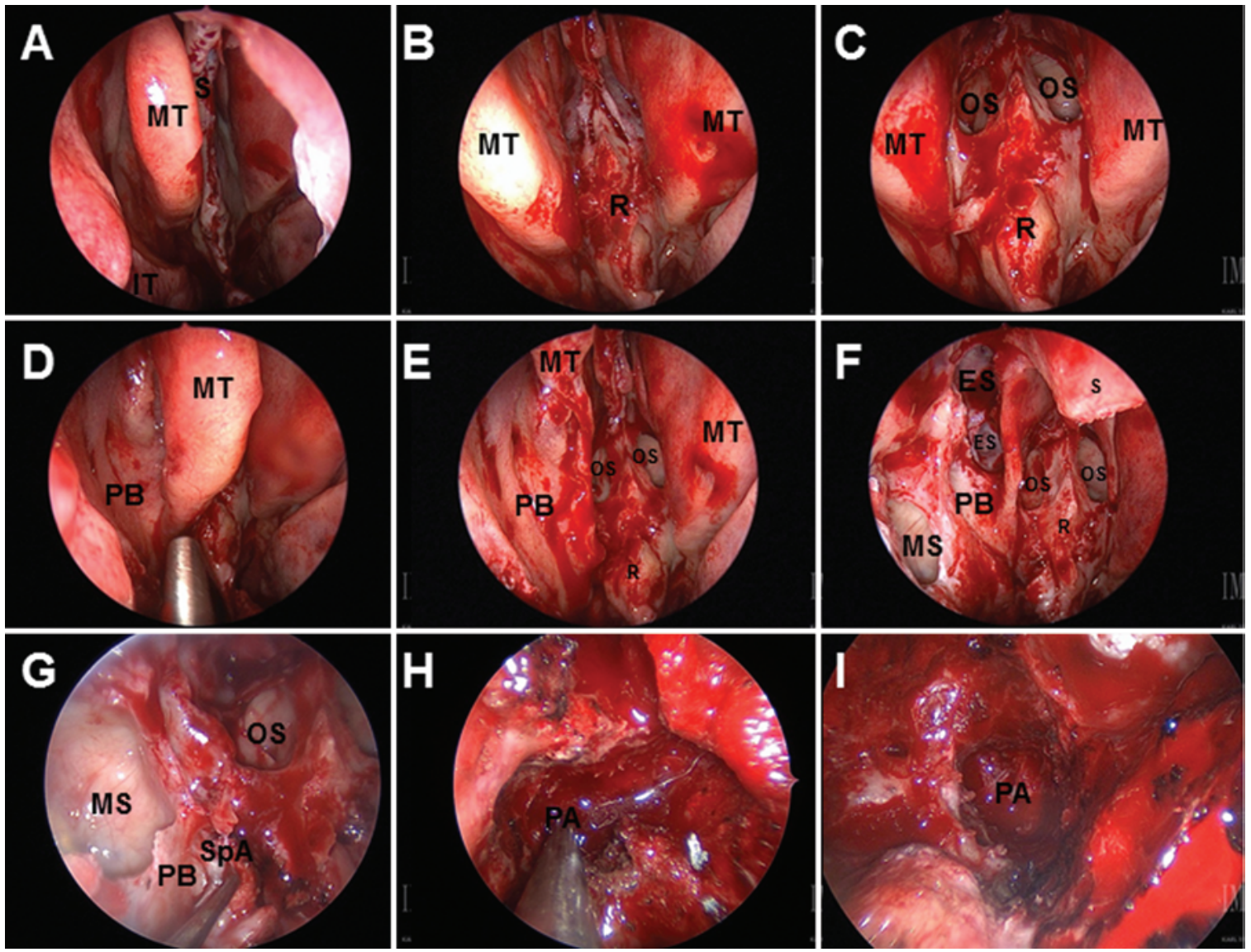

FIG. 3. Intraoperative images of an endonasal endoscopic transpterygoidal approach to resection of a chondrosarcoma. A: Septostomy has been performed and the middle turbinate is identified. B: The rostrum of sphenoid sinus is seen between the middle turbinates. C: The ostia of sphenoid sinus are identified and opened. D: The palatine bone, covered by mucosa, is visualized lateral to the middle turbinate. E: The inferior aspect of the middle turbinate is resected. F: The maxillary and ethmoid sinuses are opened. G: The sphenopalatine artery is identified and ligated, and the tumor is visualized inferomedially to the suction tip. H: The petrous apex is identified inferomedially to the pterygopalatine fossa. I: The petrous apex after removal of the chondrosarcoma. ES = ethmoid sinus; IT = inferior turbinate; $M S$ = maxillary sinus; $M T$ = middle turbinate; OS = ostium of sphenoid sinus; $P A=$ petrous apex; $\mathrm{PB}=$ palatine bone; $\mathrm{R}=$ rostrum; $\mathrm{S}=$ septum; $\mathrm{SpA}=$ sphenopalatine artery. Figure is available in color online only.

a case of meningitis arising from refractory postoperative CSF leakage. The report serves as a reminder of the seriousness of this complication and the need for meticulous techniques to prevent, identify, and treat violation of the dura during endonasal surgery.

Our data provide the largest and first multi-institutional series of the use of neuroendoscopy for treating chondrosarcoma. Our findings indicate a role for endoscopy in the treatment of paramidline anterior tumors of the skull base and of other lateral clival and petrous lesions. These data corroborate those of previous reports of treatment of other tumors in this region and demonstrate the safety and the

TABLE 3. Summary of studies reporting the use and outcomes of endoscopic endonasal resection of chondrosarcoma

\begin{tabular}{lcccccl}
\hline \multicolumn{1}{c}{ Authors \& Year } & $\begin{array}{c}\text { No. of Cases w/ } \\
\text { Chondrosarcoma }\end{array}$ & $\begin{array}{c}\text { FU Length } \\
\text { (mos) }\end{array}$ & $\begin{array}{c}\text { GTR (\%) } \\
\text { Fecurrence } \\
\text { After GTR }\end{array}$ & $\begin{array}{c}\text { Intraop CSF } \\
\text { Leakage }(\%)\end{array}$ & Complications \\
\hline Frank et al., 2006 & 2 & $27-38$ & $2(100)$ & 0 & $0(0)$ & None \\
\hline Zhang et al., 2008 & $2^{*}$ & $14-39$ & $1(50)$ & 0 & $0(0)$ & SAH in 1 of 7 patients \\
\hline $\begin{array}{l}\text { Kuge et al., 2011 } \\
\text { Li et al., 2011 }\end{array}$ & 2 & $30-50$ & $0(0)$ & NA & $2(100)$ & None \\
\hline $\begin{array}{l}\text { Fernandez-Miranda } \\
\text { et al., 2012 }\end{array}$ & 1 & 24 & $1(100)$ & 0 & $1(100)$ & CSF leakage \& meningitis requiring 3 endonasal repairs \\
\hline Present study & 18 & $1(100)$ & 0 & 0 & Eustachian tube dysfunction requiring myringotomy \\
\hline All & 16 & $1-46$ & $5(63)$ & 0 & $4(50)$ & CSF leakage requiring septal flap repair in 1 patient \\
\hline
\end{tabular}

$\mathrm{FU}=$ follow-up; $\mathrm{NA}=$ not applicable; $\mathrm{SAH}=$ subarachnoid hemorrhage.

* The series also included 5 endonasally approached clival chordomas. 
significant resection capability of our approach, which preserves and even improves neurological function. Because chondrosarcomas are soft tumors that usually spare the intradural compartment, they are typically more easily separated from neurovascular structures than other lesions of the ventral skull base such as chordoma, meningioma, or vestibular schwannoma. Our techniques to prevent CSF fistula include the use of intrathecal fluorescein to identify occult, small leaks and to monitor meticulous multilayer closure and at times lumbar drainage. Fluorescein use thus effectively minimizes one of the most important challenges arising from approaches to the endonasal skull base. ${ }^{2,16,24}$ Of note, the patient with a delayed CSF leakage did not receive intraoperative fluorescein, and no obvious leakage was identified intraoperatively. This correlation is by no means conclusive, but affirms the safety of this technique demonstrated in larger series., 2,16,24

All of our patients were referred postoperatively for adjuvant proton or proton-photon radiotherapy. Chondrosarcoma is considered to be a relatively radioresistant tumor requiring doses $>60 \mathrm{~Gy}$, which is not typically achievable with conventional external beam radiotherapy. Although the relative effectiveness of stereotactic surgery involving deployment of photon, proton, and heavier charged particles remains unclear, we use proton radiotherapy because of its availability and because its dose deposit gradient is steeper than that of photon-based methods as indicated by its increased relative biological effectiveness (that is, of 1.1). The adjuvant proton-based modality (or mixed proton-photon protocols delivering doses of up to 83 cobalt Gy equivalents) results in rates of local tumor control of $85 \%-100 \%$ at 5 years and of $83 \%$ at 10 years with limited severe toxicities (that is, $<10 \%$ Radiation Therapy Oncology Group Grade 3 or higher). ${ }^{1}$

New studies on the effectiveness of carbon-based radiotherapy (with a relative biological effectiveness of 3-5) have yielded promising results. ${ }^{14}$ One recent report with 79 cases of chondrosarcoma of the skull base suggests that carbon-based radiotherapy provides local control rates of $88 \%$ at both 5- and 10-year follow-ups, and overall survival (from the time of the histological diagnosis) of $97.5 \%$ and $91.5 \%$ at these time points, respectively. ${ }^{29,30}$

\section{Study Limitations and Future Directions}

Because chondrosarcomas in the cranial base are rare, few studies are available that have investigated the optimal treatment options for this disease, precluding largescale comparative analyses. This is reflected in the small number of cases presented in previous and in the current series, which limits the generalizability of treatment algorithms for this disease. However, by sharing our combined multi-institutional experience of the largest endoscopically treated cohort to date, we aim to further discuss the care of patients treated for chondrosarcoma. The present study reports results obtained in a relatively short follow-up period to inform the current practice of trying to achieve the goal of cytoreduction and to improve the safety of the initial treatment. Longer-term data are needed particularly for identifying the optimal radiotherapy modality and dosing given the relatively long survival of the patients with chondrosarcoma and the challenging location of these tumors.

\section{Conclusions}

Neuroendoscopy has expanded the options for treating skull base chondrosarcomas. Extended endonasal corridors to the skull base, including those offered by transethmoidal and transpterygoidal approaches, are well suited for addressing paramedian lesions such as chondrosarcomas, offering the advantage of a direct route that is less invasive than those of conventional craniotomies.

Because these chondrosarcomas are rare, few published reports are available on the management of these lesions with craniotomy, endoscopic approaches, or both. However, previous studies and the present series provide evidence that endonasal endoscopic surgery is a safe and effective approach for removing petroclival chondrosarcomas in appropriately selected patients. The approach should be selected on the basis of the tumor's medial and suprasellar extension and of its anatomic relationship with the paraclival carotid artery. Temporary CSF diversion, administration of intrathecal fluorescein, development of adequate lateral exposure, meticulous closure techniques, and avoiding optic and brain retraction all facilitate safe gross-total resection of chondrosarcomas of the skull base.

\section{References}

1. Amichetti M, Amelio D, Cianchetti M, Enrici RM, Minniti G: A systematic review of proton therapy in the treatment of chondrosarcoma of the skull base. Neurosurg Rev 33:155165,2010

2. Banu MA, Kim JH, Shin BJ, Woodworth GF, Anand VK, Schwartz TH: Low-dose intrathecal fluorescein and etiologybased graft choice in endoscopic endonasal closure of CSF leaks. Clin Neurol Neurosurg 116:28-34, 2014

3. Bloch O, Parsa AT: Skull base chondrosarcoma: evidencebased treatment paradigms. Neurosurg Clin N Am 24:8996, 2013

4. Bloch OG, Jian BJ, Yang I, Han SJ, Aranda D, Ahn BJ, et al: Cranial chondrosarcoma and recurrence. Skull Base 20:149156,2010

5. Bloch OG, Jian BJ, Yang I, Han SJ, Aranda D, Ahn BJ, et al: A systematic review of intracranial chondrosarcoma and survival. J Clin Neurosci 16:1547-1551, 2009

6. Ceylan S, Koc K, Anik I: Extended endoscopic approaches for midline skull-base lesions. Neurosurg Rev 32:309-319, 2009

7. Crockard HA, Cheeseman A, Steel T, Revesz T, Holton JL, Plowman N, et al: A multidisciplinary team approach to skull base chondrosarcomas. J Neurosurg 95:184-189, 2001

8. Dehdashti AR, Karabatsou K, Ganna A, Witterick I, Gentili F: Expanded endoscopic endonasal approach for treatment of clival chordomas: early results in 12 patients. Neurosurgery 63:299-309, 2008

9. Fernandez-Miranda JC, Morera VA, Snyderman CH, Gardner P: Endoscopic endonasal transclival approach to the jugular tubercle. Neurosurgery 71 (1 Suppl Operative):146-159, 2012

10. Frank G, Sciarretta V, Calbucci F, Farneti G, Mazzatenta D, Pasquini E: The endoscopic transnasal transsphenoidal approach for the treatment of cranial base chordomas and chondrosarcomas. Neurosurgery 59 (1 Suppl 1): ONS50-ONS57, 2006

11. Fraser JF, Nyquist GG, Moore N, Anand VK, Schwartz TH: Endoscopic endonasal transclival resection of chordomas: operative technique, clinical outcome, and review of the literature. J Neurosurg 112:1061-1069, 2010

12. French KF, Martinez JK, Dehavenon AH, Weathered NR, 
Grantz M, Smith SM, et al: Reproducibility of ABC/2 method to determine infarct volume and mismatch percentage with CT perfusion. J Neuroimaging 24:232-237, 2014

13. Gay E, Sekhar LN, Rubinstein E, Wright DC, Sen C, Janecka IP, et al: Chordomas and chondrosarcomas of the cranial base: results and follow-up of 60 patients. Neurosurgery 36:887-897, 1995

14. Grün R, Friedrich T, Elsässer T, Krämer M, Zink K, Karger $\mathrm{CP}$, et al: Impact of enhancements in the local effect model (LEM) on the predicted RBE-weighted target dose distribution in carbon ion therapy. Phys Med Biol 57:7261-7274, 2012

15. Hofstetter CP, Singh A, Anand VK, Kacker A, Schwartz TH: The endoscopic, endonasal, transmaxillary transpterygoid approach to the pterygopalatine fossa, infratemporal fossa, petrous apex, and the Meckel cave. J Neurosurg 113:967-974, 2010

16. Jakimovski D, Bonci G, Attia M, Shao H, Hofstetter C, Tsiouris AJ, et al: Incidence and significance of intraoperative cerebrospinal fluid leak in endoscopic pituitary surgery using intrathecal fluorescein. World Neurosurg 82:e513e523, 2014

17. Jiang WH, Zhao SP, Xie ZH, Zhang H, Zhang J, Xiao JY: Endoscopic resection of chordomas in different clival regions. Acta Otolaryngol 129:71-83, 2009

18. Kasemsiri P, Solares CA, Carrau RL, Prosser JD, Prevedello DM, Otto BA, et al: Endoscopic endonasal transpterygoid approaches: anatomical landmarks for planning the surgical corridor. Laryngoscope 123:811-815, 2013

19. Kassam AB, Gardner P, Snyderman C, Mintz A, Carrau R: Expanded endonasal approach: fully endoscopic, completely transnasal approach to the middle third of the clivus, petrous bone, middle cranial fossa, and infratemporal fossa. Neurosurg Focus 19(1):E6, 2005

20. Kuge A, Sato S, Sakurada K, Takemura S, Kikuchi Z, Saito Y, et al: Technical notes on endoscopic transnasal transsphenoidal approach for clival chondrosarcoma. Sarcoma 2011:953047, 2011

21. Li MC, Guo HC, Chen G, Kong F, Zhang QH: Meningitis caused by Enterococcus casseliflavus with refractory cerebrospinal fluid leakage following endoscopic endonasal removal of skull base chondrosarcoma. Chin Med J (Engl) 124:3440, 2011 (Letter)

22. Neff B, Sataloff RT, Storey L, Hawkshaw M, Spiegel JR: Chondrosarcoma of the skull base. Laryngoscope 112:134139,2002

23. Oghalai JS, Buxbaum JL, Jackler RK, McDermott MW: Skull base chondrosarcoma originating from the petroclival junction. Otol Neurotol 26:1052-1060, 2005

24. Placantonakis DG, Tabaee A, Anand VK, Hiltzik D, Schwartz TH: Safety of low-dose intrathecal fluorescein in endoscopic cranial base surgery. Neurosurgery 61 (3 Suppl):161-166, 2007
25. Samii A, Gerganov V, Herold C, Gharabaghi A, Hayashi N, Samii M: Surgical treatment of skull base chondrosarcomas. Neurosurg Rev 32:67-75, 2009

26. Sekhar LN, Pranatartiharan R, Chanda A, Wright DC: Chordomas and chondrosarcomas of the skull base: results and complications of surgical management. Neurosurg Focus 10(3):E2, 2001

27. Sen CN, Sekhar LN, Schramm VL, Janecka IP: Chordoma and chondrosarcoma of the cranial base: an 8-year experience. Neurosurgery 25:931-941, 1989

28. Stippler M, Gardner PA, Snyderman CH, Carrau RL, Prevedello DM, Kassam AB: Endoscopic endonasal approach for clival chordomas. Neurosurgery 64:268-278, 2009

29. Uhl M, Mattke M, Welzel T, Oelmann J, Habl G, Jensen AD, et al: High control rate in patients with chondrosarcoma of the skull base after carbon ion therapy: first report of longterm results. Cancer 120:1579-1585, 2014

30. Uhl M, Welzel T, Oelmann J, Habl G, Hauswald H, Jensen A, et al: Active raster scanning with carbon ions: reirradiation in patients with recurrent skull base chordomas and chondrosarcomas. Strahlenther Onkol 190:686-691, 2014

31. Wanebo JE, Bristol RE, Porter RR, Coons SW, Spetzler RF: Management of cranial base chondrosarcomas. Neurosurgery 58:249-255, 2006

32. Zanation AM, Snyderman CH, Carrau RL, Gardner PA, Prevedello DM, Kassam AB: Endoscopic endonasal surgery for petrous apex lesions. Laryngoscope 119:19-25, 2009

33. Zhang Q, Kong F, Yan B, Ni Z, Liu H: Endoscopic endonasal surgery for clival chordoma and chondrosarcoma. ORL J Otorhinolaryngol Relat Spec 70:124-129, 2008

\section{Author Contributions}

Conception and design: Schwartz, Moussazadeh. Acquisition of data: Schwartz, Moussazadeh, Kulwin, Anand, Ting, Gamss, Tsiouris, Cohen-Gadol. Analysis and interpretation of data: Schwartz, Moussazadeh, Kulwin, Anand, Ting, Gamss, Tsiouris, Cohen-Gadol. Drafting the article: all authors. Critically revising the article: Schwartz, Moussazadeh, Kulwin, Anand, Ting, Gamss, Tsiouris, Cohen-Gadol. Reviewed submitted version of manuscript: all authors. Approved the final version of the manuscript on behalf of all authors: Schwartz. Study supervision: Schwartz.

\section{Correspondence}

Theodore H. Schwartz, Department of Neurological Surgery, Weill Cornell Medical College, NewYork-Presbyterian Hospital, 525 East 68th St., Box \#99, New York, NY 10065. email: schwarh@med.cornell.edu. 